\title{
Role of age and length of oestrous cycle in alteration of the oocyte and intrauterine environment in the rat
}

\author{
R. D. Page*, Diana Kirkpatrick-Keller and R. L. Butcher \\ Department of Obstetrics and Gynecology, West Virginia University School of Medicine, \\ Morgantown, West Virginia 26506, U.S.A.
}

\begin{abstract}
Summary. Zygotes were transferred, on the day of fertilization, from young and old rats with 4- or 6-day oestrous cycles into the ovarian bursa of young recipients with 4-day cycles, and zygotes from young rats with 4-day cycles were transferred into young and old recipients with 4-or 6-day cycles. Young rats with 4-day cycles served as controls for both donors and recipients. An increase in length of cycle or maternal age of donor caused an increase in unfertilized and/or abnormal eggs at the pronuclear stage (nontransferred zygotes). Increased age of donor or length of cycle decreased the implantation rate observed on Day 11 of pregnancy. Likewise, increased age of recipient or length of cycle decreased implantation rate observed on Day 11 of pregnancy. The increase in both age and length of cycle of donor or recipient caused the greatest decline in implantation rate and percentage of normal embryos observed on Day 11 of pregnancy.
\end{abstract}

\section{Introduction}

Mature female rats exhibit oestrous cycles of 4 or 5 days in length, until 10-12 months of age. At this age, they begin to show oestrous cycles of abnormal lengths (Lu, Hopper, Vargo \& Yen, 1979), including cycles of 6 days (a natural delay of ovulation). Abnormal embryonic development increases in aged rats, with more abnormalities occurring when the length of cycle is 6 days, than when it is 4 or 5 days (Fugo \& Butcher, 1971). Decreased fertilization rate, increased embryonic anomalies and increased embryonic resorption are consequences of this natural delay of ovulation. Delay of ovulation in young rats can be induced experimentally with pentobarbitone sodium (Everett \& Sawyer, 1950) and results in an increase in chromosomal anomalies (Butcher \& Fugo, 1967) as well as morphologically abnormal embryonic and fetal development (Fugo \& Butcher, 1966; Butcher, Blue \& Fugo, 1969).

It has been proposed that the effect of delayed ovulation on developmental anomalies and pregnancy loss is mediated, at least in part, by an increased exposure of the intrafollicular oocyte to oestradiol (Butcher, Collins \& Fugo, 1975; Butcher \& Pope, 1979; Butcher \& Page, 1981 ; Page \& Butcher, 1982). Effects of intrauterine environment also contributed to pregnancy loss in old animals (Butcher \& Page, 1981). Talbert \& Krohn (1966) reported that only $14 \%$ of zygotes from young mice survived to term in old hosts compared to $48 \%$ surviving to term in young hosts. Butcher et al. (1969) performed reciprocal transfers of blastocysts between young rats with 4-day cycles and young rats in which ovulation had been delayed (6-day cycles). Compared to control transfers

* Present address: Department of Animal and Dairy Science, University of Georgia, Athens, Georgia 30602,U.S.A. 
between donors and recipients with 4-day cycles, an induced delay of ovulation in young rats caused detrimental changes in the zygotes and in the intrauterine environment. Because transfers were performed at the blastocyst stage, effects due to the oocyte could not be separated from those of oviducal and uterine environment during the 4 days before transfer. Although the developmental potential of the blastocyst has been reported not to be influenced by the endocrine status of the oviduct (Beyer \& Zeilmaker, 1973), contribution of the oviduct due to age or length of oestrous cycle has not been assessed.

The present experiment was designed to separate effects of intrafollicular ageing of the oocyte from effects of intraoviducal/intrauterine environment by transferring zygotes into the ovarian bursa within 3-5 h after fertilization. Moreover, by using young and old rats with normal oestrous cycles and with delayed ovulation, effects of both maternal age and of delayed ovulation can be evaluated.

\section{Materials and Methods}

Animals. Young (170-200 g) and old (retired breeders $>1$ year of age) female Holtzman rats were housed under controlled temperature, humidity and lighting. All animals received $12 \mathrm{~h}$ light per day. However, the lighting schedules in the rooms for donors and recipients were different, for at least 14 days before beginning the experiment; lights were on from $06: 00$ to 18:00 $\mathrm{h}$ for donors and 10:00 to $22: 00 \mathrm{~h}$ for recipients. In preliminary experiments, an increase in pregnancy rate was obtained when the lighting schedule for the recipients was delayed by $4 \mathrm{~h}$ compared to that of the donors. The difference in lighting schedule allowed eggs from donors to be collected 3-5 h after fertilization (6-8 h after ovulation) and to be transferred into recipients that were $2-4 \mathrm{~h}$ after ovulation. The time of transfer of zygotes was limited to the period of $09: 30-10: 30 \mathrm{~h}$.

The four types of animals used were young rats with 4-day oestrous cycles (Y4), young rats with 4-day cycles in which ovulation was delayed for 2 days by treatment with pentobarbitone sodium (Everett \& Sawyer, 1950) to produce 6-day cycles (Y6), old rats with 4-day cycles (O4) and old rats with spontaneous 6-day cycles (O6). Zygotes from rats of each of the 4 groups were transferred into Y4 recipients to study the effects of age and length of oestrous cycle on the oocyte. Also, each type of animal served as recipient for zygotes collected from Y4 donors to examine for effects of age and length of cycle on intrauterine environment. Young rats that did not maintain oestrous cycles of 4 days in length were not used in these experiments. Old rats were required to have exhibited at least 2 previous oestrous cycles of 6 days or longer before use. The contributions of the oocyte and the intrauterine environment were assessed at Day 11 of gestation by implantation rate, postimplantation death and embryonic development.

Transfer of zygotes. Vaginal smears were taken daily between 08:00 and 10:00 h to determine the length and stage of oestrous cycle. Each donor female was housed with a fertile male from the afternoon of pro-oestrus to $08: 00 \mathrm{~h}$ on the day of oestrus. A vaginal smear containing spermatozoa on the day of oestrus confirmed mating (Day 0). Each recipient female was placed with a vasectomized male on the afternoon of pro-oestrus, and the finding of a vaginal plug under the breeding cage or in the vagina the following day confirmed mating. Vaginal smears were taken daily after the day of transfer to confirm that pseudopregnancy had been induced in the recipient.

Donor females were killed by decapitation. The ovary, oviduct and a small portion of the uterus were removed from each side of the reproductive tract and placed in saline $(0.9 \%(\mathrm{w} / \mathrm{v}) \mathrm{NaCl})$ at $37^{\circ} \mathrm{C}$. Syringes, glassware and saline were at $37^{\circ} \mathrm{C}$ at the onset of each transfer, but gradually cooled to room temperature (Dickmann, 1971). The uterine remnant was removed from the oviduct, which was then placed in an embryonic watch glass and observed under a dissecting microscope. Zygotes were collected by one of two methods: (1) the swollen ampullary region of the oviduct was opened with fine forceps and the eggs covered with cumulus cells flowed out with slight pressure on the oviduct, (2) the ovarian bursa was opened, a blunt 27-gauge needle (attached to a $1 \mathrm{ml}$ syringe) 
was inserted into the ovarian end of the oviduct (ostium tubae) and the zygotes were flushed from the oviduct with $0.5-1.0 \mathrm{ml}$ saline. Embryos were washed in saline before transfer to reduce the probability of transferring spermatozoa. Also, to ensure absence of cross fertilization, 15 transfers were made between genetically marked donors (Long-Evans hooded rats with dark pigmented eyes mated to albino Holtzman males) and Holtzman recipients. All 44 fetuses resulting from these transfers had dark eyes when recovered at Day 19 of gestation, indicating that fertilization of the recipient's oocytes did not occur.

Transfer of zygotes into recipients was accomplished using a capillary glass tube attached to a $10 \mu \mathrm{l}$ Hamilton syringe. The washed zygotes to be transferred into one ovarian bursa (3-7 per side, maximum of 10 per recipient) were collected into a glass tube in $<3 \mu$ l saline. The capillary tube was inserted through the small bursal foramen which opens caudally to the utero-oviducal junction (Alden, 1942), and the zygotes were deposited into the bursal cavity. Halothane anaesthesia was used for the surgery; and transfers were completed within 15 min after death of the donor. After surgery, recipients were housed in stock cages with other females. Because the time for transfers was limited to $09: 30$ to $10: 30 \mathrm{~h}$, no more than 4 transfers were done in 1 day.

Recipient animals were killed by decapitation on Day 11 of gestation and the number and relative size of implantation sites were noted. The uterus was opened on the antimesometrial side with care not to rupture the embryonic membranes, placed in Bouin's fixative overnight, and then stored in $70 \%$ ethanol. After removal of the embryonic membranes, the embryos were examined for normality of size and development. Abnormalities were based on development-for-size of previously studied rat embryos from 9-12 days of gestation, with the most frequent anomalies being gross malformations, open neural tube and disproportionate growth (e.g. underdeveloped head). The size of each embryo was evaluated by the use of calibrated lines on the bottom of a Petri dish.

Evaluation of eggs. When more donors than recipient rats were available, the excess donors were killed, the eggs recovered and the cumulus cells dispersed with a few drops of $2 \%$ trypsin. Eggs in $0.9 \% \mathrm{NaCl}$ were placed on a microscope slide with an interrupted vaseline-paraffin wax ring to support the cover slip (Fugo \& Butcher, 1966) and were evaluated under phase-contrast microscopy at $\times 600$ for number of pronuclei, number of sperm tails within the egg, number of accessory spermatozoa, number and size of polar bodies and other anomalies of the zygote.

Statistical analyses. Data were analysed for differences in fertilization rate and normality of zygotes at the 1-cell stage and for differences in pregnancy rate, implantation rate, embryonic survival and normality of embryonic development at Day 11 of gestation. Overall differences in numbers per group were assessed by $\chi^{2}$ tests. Percentages for each variable to be analysed were calculated for each rat, and two-way analysis of variance (ANOVA) with age and length of oestrous cycle as main effects was used to compare results of morphology of non-transferred zygotes and for comparisons within donor and recipient groups. When significance was found with the ANOVA, differences between group means were assessed by least significant difference (LSD) (Snedecor \& Cochran, 1967).

\section{Results}

Data from morphological evaluation of non-transferred embryos at the 1-cell (pronuclear) stage are presented in Table 1. Compared to zygotes from Y4 animals, the fertilization rate was decreased ( $P$ $<0.05)$ in the other three groups. The percentage of zygotes classified as abnormal was increased in both groups of old rats. ANOVA showed a significant effect of age of rat on normality of embryos. From analysis by LSD, there was a significant increase in abnormal zygotes when comparisons were made between embryos from $\mathrm{Y} 4$ or $\mathrm{Y} 6$ and $\mathrm{O} 4$ or $\mathrm{O} 6$ rats. The incidence of polyspermy increased, though not significantly, due to age of rat and length of cycle $(0.8,1 \cdot 2,1.7$ and $3.7 \%$ for Y4, Y6, O4 and O6 rats, respectively).

Data on pregnancy, implantation and embryonic development at Day 11 after transfer of 
Table 1. Effects of age and length of oestrous cycle in rats on fertilization rate and developmental anomalies at the pronuclear stage

\begin{tabular}{ccccc}
\hline & & \multicolumn{3}{c}{ No. of eggs } \\
\cline { 3 - 5 } Group & $\begin{array}{c}\text { No. of } \\
\text { rats }\end{array}$ & Examined & Unfertilized§ & $\begin{array}{c}\text { Fertilized but } \\
\text { abnormal§ }\end{array}$ \\
\hline Y4 & 22 & 270 & $5(2 \pm 1)$ & $9(3 \pm 2)$ \\
Y6 & 13 & 162 & $48(26 \pm 11)^{*}$ & $2(1 \pm 1)$ \\
O4 & 11 & 113 & $23(16 \pm 9)^{*}$ & $11(15 \pm 7)^{*} \dagger$ \\
O6 & 10 & 109 & $21(19 \pm 10)^{*}$ & $8(12 \pm 4)^{*} \ddagger$ \\
\hline
\end{tabular}

$\S$ Values are total no./group. Percentages were calculated for each rat and the mean \pm s.e.m. $\%$ is shown in parentheses.

* $P<0.05$ compared to Y4 ( $\chi^{2}$ using total no./group).

$\dagger P<0.05$ compared to Y4 (LSD).

$\ddagger P<0.05$ compared to Y6 (LSD).

zygotes are shown in Table 2. There were no'differences in number of pregnancies due to type of donor, but the number of rats establishing a pregnancy was decreased $(P<0.05)$ in 06 recipients compared to the other 3 types of recipients. However, compared to control transfers, the number of embryos implanting was decreased $(P<0.05)$ in all other donor and recipient groups. There also was a decrease in implantation rate in 06 recipients $(P<0.05)$ compared to all other groups. Even after eliminating the data from rats without implantation sites, there was still a decreased percentage of embryos implanting (data not shown) in groups with Y6 and $\mathrm{O} 4$ donors and $\mathrm{O} 6$ recipients. Post-implantation survival (\% implantations as embryos) did not differ $(P<0.05)$ among groups, whether analysed by ANOVA or $\chi^{2}$ or whether all rats with implantation sites or only rats with one or more surviving embryos were used in comparisons. However, the number of recovered embryos classified as normal was reduced when the donor was an O6 rat $(P<0.05)$ or the recipient was an 04 or O6 rat $(P<0.05)$. By ANOVA, there was a significant effect of age of recipient which, when analysed by LSD, was significant $(P<0.05)$ for $\mathrm{O} 4$ or O6 compared to Y 4 or Y6 recipients.

Table 2. Effects of age and length of oestrous cycle of donor and recipient rats on implantation and embryonic development of transferred zygotes, as determined at Day 11 of gestation

\begin{tabular}{|c|c|c|c|c|c|c|c|}
\hline Donor & Recipient & $\begin{array}{c}\text { No. of } \\
\text { zygotes } \\
\text { transferred }\end{array}$ & $\begin{array}{l}\text { No. of rats } \\
\text { pregnant/ } \\
\text { total no. }\end{array}$ & $\begin{array}{l}\text { No. }(\%) \S \\
\text { of zygotes } \\
\text { implanting }\end{array}$ & $\begin{array}{c}\text { No. }(\%) \S \\
\text { implantations } \\
\text { as embryos }\end{array}$ & $\begin{array}{l}\text { No. of } \\
\text { embryos } \\
\text { examined }\end{array}$ & $\begin{array}{l}\text { No. }(\%) \S \\
\text { of normal } \\
\text { embryos }\end{array}$ \\
\hline \multicolumn{8}{|c|}{ Effects of donor } \\
\hline Y4 & Y4 & 193 & $18 / 20$ & $103(53 \pm 7)$ & $72(65 \pm 8)$ & 72 & $66(95 \pm 2)$ \\
\hline Y6 & Y4 & 184 & $17 / 20$ & $71(38 \pm 7)^{*}$ & $58(81 \pm 6)$ & 58 & $51(86 \pm 7)$ \\
\hline $\mathrm{O} 4$ & Y4 & 195 & $19 / 21$ & $80(40 \pm 6)^{*}$ & $61(72 \pm 7)$ & 61 & $46(85 \pm 7)$ \\
\hline O6 & Y4 & 174 & $15 / 19$ & $67(37 \pm 7)^{*}$ & $42(58 \pm 10)$ & 42 & $33(81 \pm 9)^{*}$ \\
\hline \multicolumn{8}{|c|}{ Effects of recipient } \\
\hline Y4 & Y4 & 193 & $18 / 20$ & $103(53 \pm 7)$ & $72(65 \pm 8)$ & 72 & $66(95 \pm 2)$ \\
\hline Y4 & Y6 & 181 & $16 / 20$ & $69(34 \pm 7)^{*}$ & $52(70 \pm 7)$ & 52 & $48(96 \pm 3)$ \\
\hline Y4 & $\mathrm{O} 4$ & 187 & $15 / 20$ & $75(40 \pm 7)^{*}$ & $49(63 \pm 7)$ & 49 & $32(67 \pm 10)^{*} \ddagger$ \\
\hline Y4 & O6 & 192 & $9 / 20 \dagger$ & $24(12 \pm 4)^{*}+$ & $13(49 \pm 11)$ & 13 & $7(43 \pm 20)^{*} \ddagger$ \\
\hline
\end{tabular}

$\S$ Values are total no./group. Percentages were calculated for each rat and the mean \pm s.e.m. $\%$ is shown in parentheses.

${ }^{*} P<0.05$ compared to Y4-Y4 ( $\chi^{2}$ using total no./group).

$\dagger P<0.05$ compared to $\mathrm{Y} 4, \mathrm{Y} 6$ and $\mathrm{O} 4$ recipients (LSD).

$\ddagger P<0.05$ compared to $\mathrm{Y} 4$ or $\mathrm{Y} 6$ recipients (LSD). 


\section{Discussion}

The transfer of zygotes was used in the present study to separate the effects of age of rat and length of the oestrous cycle on the oocyte and intrauterine environment, as evaluated by pregnancy rate, implantation and embryonic development. By selection of the time of transfer and use of the bursal foramen for depositing of ova into the ovarian bursa within 3-5 h after fertilization, implantation rates $(53 \%)$ approached those observed using transfer of blastocysts into the uterus. Preliminary transfers, in which both the donor and recipient were approximately $6-8 \mathrm{~h}$ after ovulation, yielded limited success. When the lighting schedule for recipients was delayed $4 \mathrm{~h}$ from that of the donors, and the transfers performed between $09: 30$ and $10: 30 \mathrm{~h}$, i.e. recipients were $2-4 \mathrm{~h}$ after ovulation, the success rate greatly improved. Casual observations indicated a greater contractile activity of the recipient uterus and oviduct at the time of transfer when the staggered lighting schedules were used.

From the results of morphological evaluation of non-transferred eggs, it was concluded that an increase in length of cycle and increase in age of rat caused a decrease in fertilization rate, while an increase in age led to increases in abnormalities at the pronuclear stage. An increase in length of cycle has previously been shown (Page \& Butcher, 1982) to be associated with an early increase in intrafollicular as well as plasma concentration of oestradiol in relation to the time of ovulation. An early increase in oestradiol in animals with induced delay of ovulation has been shown to decrease implantation rate (Butcher \& Pope, 1979). The early increase in follicular oestradiol before ovulation may detrimentally affect the intrafollicular oocyte, thus contributing to the decrease in fertilization rate in the Y6 and $\mathrm{O} 6$ rats. The mechanism by which age contributes to oocyte abnormalities has not been determined. However, Page \& Butcher (1982) proposed that, in old rats with oestrous cycles of normal length, an early development of follicles resulted in altered oestradiol patterns, which could affect the oocytes and the uterus.

There was a reduction in number of pregnant animals on Day 11 only in O6 recipients as compared to the Y4-Y4 group, although more of the transferred zygotes resulted in implantation sites in $\mathrm{Y} 4-\mathrm{Y} 4$ than in any other group. A reduction in implantation rate due to increased age or length of cycle of donor can be accounted for in part by the decreased fertilization rate observed at the 1-cell stage. However, the decline in implantation rate due to age and length of cycle of recipient was independent of fertilization rate, as all embryos transferred to the recipients were from Y4 donors. Therefore, the decreased implantation rate in these recipients was probably due to detrimental effects of the oviducal and uterine environments on embryonic survival before implantation. Although the incidence of post-implantation death of transferred zygotes was much greater than normally found in young unoperated rats, there was no difference due to age or length of oestrous cycle of donor or of recipient. This is in contrast to an increase in post-implantation loss when cycles were 6 days in length in young and old rats in previous studies (Fugo \& Butcher, 1966, 1971). Detrimental effects of the transfer procedure, or of the recipient oviduct, on defective zygotes could have produced preimplantation rather than post-implantation loss; whole normal zygotes could have been affected equally in each group to cause similar rates of post-implantation death. The lower incidence of abnormal embryos at Day 11, and the higher embryonic death in all groups compared to earlier studies, lends support to this proposal. The effect on the oviduct and uterus of an early increase in oestradiol in relation to time of ovulation has been proposed (Page \& Butcher, 1982) as a possible cause of detrimental effects of the environment within the reproductive tract on embryonic death, both pre- and post-implantation.

In conclusion, increases both in age of rat and length of the oestrous cycle cause changes in the oocyte which decrease fertilization rate. Age and length of cycle of the recipient influence implantation rate and post-implantation embryonic development. These changes in the oocyte and reproductive tract could be caused by an inappropriate sequence of oestrogen in relation to the time of ovulation.

We thank Dr William V. Thayne for statistical analyses and Mrs Patricia Lutsie and Mrs Claire Messina for their excellent technical assistance. This investigation was supported by NIH 
Research Grant AG-02311 from the National Institute of Aging (R.L.B.). R.D.P. was a Postdoctoral Fellow supported by NIH Postdoctoral Training Grant T32-AM-07312.

\section{References}

Alden, R.H. (1942) The periovarial sac in the albino rat. Anat. Rec. 83, 421-435.

Beyer, G. \& Zeilmaker, G.H. (1973) Development of mouse and rat zygotes following transfer to nonsynchronized rat and mouse oviducts. J. Reprod. Fert. 33, 141-143.

Butcher, R.L. \& Fugo, N.W. (1967) Overripeness and the mammalian ova. Il. Delayed ovulation and chromosomal anomalies. Fert. Steril. 18, 297-302.

Butcher, R.L. \& Page, R.D. (1981) Role of the aging ovary in cessation of reproduction. In Dynamics of Ovarian Function, pp. 253-271. Eds N. Schwartz \& M. Hunzicker-Dunn. Raven Press, New York.

Butcher, R.L. \& Pope, R.S. (1979) Role of estrogen during prolonged estrous cycles of the rat on subsequent embryonic death or development. Biol. Reprod. 21, 491-495.

Butcher, R.L., Blue, J.D. \& Fugo, N.W. (1969) Role of intrauterine environment on ova after normal and delayed ovulation. Biol. Reprod. 1, 149-151.

Butcher, R.L., Collins, W.E. \& Fugo, N.W. (1975) Altered secretion of gonadotropins and steroids resulting from delayed ovulation in the rat. Endocrinology 96, 576-586.

Dickmann, Z. (1971) Egg transfer. In Methods in Mammalian Embryology, pp. 133-145. Ed. J. C. Daniel, Jr. W. H. Freeman and Co., San Francisco.
Everett, J.W. \& Sawyer, C.H. (1950) A 24-hour periodicity in the "LH-release apparatus" of female rats, disclosed by barbiturate sedation. Endocrinology 47, $198-218$.

Fugo, N.W. \& Butcher, R.L. (1966) Overripeness and the mammalian ova. I. Overripeness and early embryonic development. Fert. Steril. 17, 804-814.

Fugo, N.W. \& Butcher, R.L. (1971) Effects of prolonged estrous cycles on reproduction in aged rats. Fert. Steril. 22, 98-101.

Lu, K.H., Hopper, B.R., Vargo, T.M. \& Yen, S.S.C. (1979) Chronological changes in sex steroid, gonadotropin and prolactin secretion in aging female rats displaying different reproductive states. Biol. Reprod. 21, 193-203.

Page, R.D. \& Butcher, R.L. (1982) Follicular and plasma patterns of steroids in young and old rats during normal and prolonged estrous cycles. Biol. Reprod. 27, 383-392.

Snedecor, G.W. \& Cochran, W.G. (1967) Statistical Methods, pp. 258-338. Iowa State University Press, Ames.

Talbert, G.B. \& Krohn, P.L. (1966) Effect of maternal age on viability of ova and uterine support of pregnancy in mice. J. Reprod. Fert. 11, 399-406.

Received 15 November 1982 